\title{
Monkeying around with HIV vaccines: using rhesus macaques to define 'gatekeepers' for clinical trials
}

\section{Devon J. Shedlock, Guido Silvestri and David B. Weiner}

\begin{abstract}
Rhesus macaques are an important animal model for the study of human disease and the development of vaccines against HIV and AIDS. HIV vaccines have been benchmarked in rhesus macaque preclinical challenge studies using chimeric viruses made up of parts of HIV and simian immunodeficency viruses. However, the lack of efficacy in a recent clinical trial calls for a re-evaluation of the scientific assumptions regarding the predictive value of using data generated from rhesus macaques as a 'gatekeeper' for the advancement of candidate vaccines into the clinic. In this context, there is significant consensus among HIV vaccinologists that next-generation HIV vaccines must generate 'better' immunity in rhesus macaques than clinically unsuccessful vaccines generated using validated assays. Defining better immunity is the core challenge of HIV vaccine development in this system and is the focus of this Review.
\end{abstract}

\section{Model}

The observed or predicted behaviour of a system used for the basis of simulation. Models allow the understanding of complex systems and prediction of their behaviour. A model may give incorrect descriptions and predications for situations outside the realm of its intended use.
Department of Pathology and Laboratory Medicine, University of Pennsylvania School of Medicine, Philadelphia, Pennsylvania 19104, USA. Correspondence to D.B.W. e-mail:dbweiner@mail.med. upenn.edu

doi:10.1038/nri2636
HIV and AIDS is a global pandemic that has claimed many millions of lives since the disease was first described in 1981. Today, it is estimated that over 33 million people are living with HIV (see the UNAIDS 2008 report on the global AIDS epidemic), despite exhaustive efforts to control the spread of the infection. Although improved education programmes, barrier techniques and antiretroviral therapies help to decrease the virus transmission and mortality rates, a large number of HIV-infected individuals cannot obtain antiretroviral drugs, which are customized, expensive and often inaccessible. It is widely agreed that a vaccine that prevents or controls HIV infection would help to control this devastating epidemic. However, such a vaccine remains elusive.

In light of the failure of a recent clinical trial of a leading Merck \& Co. HIV vaccine (the STEP trial), reevaluation of the use of non-human primate models for HIV vaccine preclinical development is important ${ }^{1-3}$. The relevance of the rhesus macaque model to human HIV vaccine development has been recently reviewed in articles that focused for the most part on the similarities between rhesus macaques and humans ${ }^{4-7}$. However, although we agree that the use of animal models for the study of HIV and AIDS is crucial for understanding viral immunobiology and for the rational design of vaccines and therapies, we also need to consider that there are important differences between these two species that should not be ignored.
Historically, the use of animal models for the study of human disease has had obvious advantages: fundamental properties of the disease can be investigated more invasively and thoroughly, while drug and vaccine toxicity and efficacy studies can provide proof-of-concept for advancing trials into human subjects, limiting the risk, time and cost of clinical trials ${ }^{4}$. Preclinical data generated in animal models serve collectively as a gatekeeper for the progression of candidate vaccines to evaluation in a clinical setting. Researchers have made a considerable effort to generate animal models for human diseases, even when this endeavour is not straightforward, as is the case for HIV and AIDS 4 . The major limitation surrounding HIV study in animal models is that the virus does not replicate in most animal species tested, including rodents ${ }^{8}$ and non-human primates ${ }^{4}$ (the rare exceptions being gibbon apes and chimpanzees; however, in these animals HIV-1 infection is typically not associated with clinical diseases and haematological abnormalities ${ }^{2,4}$ ). Although chimpanzees are the closest species in evolutionary terms to humans, they are endangered, they are costly to maintain and their use can be of ethical concern. Thus, the focus has shifted to viral surrogates of HIV, simian immunodeficiency viruses (SIVs), for which infection in natural non-human primate hosts, such as sooty mangabeys and African green monkeys, is generally non-pathogenic ${ }^{9,10}$, but experimental 
infection of non-natural hosts, such as Asian monkey species, including rhesus macaques (Macaca mulatta), results in the development of disease similar to that described in patients with AIDS (simian AIDS) ${ }^{11}$.

Studies carried out in the late 1980s and early 1990s were greeted with excitement when recombinant live vaccines $^{12}$ and DNA vaccines ${ }^{13-15}$ elicited measurable CD8 ${ }^{+}$ cytotoxic T lymphocyte (CTL) responses in both rhesus macaques ${ }^{16}$ and humans, and recombinant protein- and peptide-based vaccines induced measurable levels of neutralizing antibodies ${ }^{16-19}$. However, Phase III clinical studies showed that recombinant HIV envelope (Env)expressing vaccines could not stimulate antibodies that had a broad enough spectrum to protect against viral transmission, even against closely matched viruse ${ }^{20,21}$. It soon became evident that similar vaccines capable of eliciting neutralizing antibodies against chimeric HIV Envexpressing SIVs (SHIVs) in non-human primates ${ }^{22-25}$ could not protect rhesus macaques against subsequent challenge with divergent SHIVs, and SIVmac was resistant to neutralization. ${ }^{26-29}$. Based on these findings, the hope for a quick solution to the HIV vaccine problem through the induction of neutralizing antibody responses faded dramatically.

As a result, many researchers in the field refocused their studies to develop immunization approaches based on exploiting antiviral T cell responses. Preliminary evidence in non-human primates supported the notion that such a vaccine-engineered response might limit, at least partially, challenges with SIV strains that were distinct to the vaccine strain. This shift in thinking was accompanied by a focus on the development of potent vector systems for inducing HIV-specific CTL responses. Of note, the goal of these vaccines was not to induce sterilizing immunity, but rather to decrease the rate of disease progression after infection by lowering virus load. This second-generation vaccine strategy included the study of advanced recombinant viral vectors such as adenovirus vectors expressing HIV and/or SIV proteins, and could stimulate strong CTL responses alone as well as in heterologous primeboost immunization protocols in primates, which have been standard for most of the past decade. Preclinical studies of these adenovirus-based vaccines in rhesus macaques were promising and induced protection (defined as lower viral loads or greater survival after challenge than in nonvaccinated control animals) against SHIV challenges ${ }^{22,25}$, thus generating considerable optimism. However, concerns were raised regarding the rapid pathogenesis and unusual co-receptor usage by specific SHIVs or the complete lack of pathogenesis of other SHIVs. Subsequent studies showed that this vaccine approach offered little protection against pathogenic SIV challenge when administered to outbred genetic haplotypes ${ }^{26}$.

Despite the ensuing debate regarding the relevance of various SIV and SHIV challenge models to human HIV infection, adenovirus serotype 5 (Ad5) studies advanced into clinical trials for efficacy based on the assumptions that protection (defined as lower peak viral loads and viral set point with delayed progression to disease) in rhesus macaques against pathogenic SHIV challenge equates to protection in humans, and non-protection in rhesus macaques equates to non-protection in humans. The STEP Phase IIb clinical trial evaluated the efficacy of a replication-incompetent Ad5-based vaccine encoding HIV Gag, Pol and Nef in stratified Ad5-seropositive individuals living in the Americas and Australia ${ }^{30}$. However, the vaccine showed a complete lack of efficacy in preventing either infection or disease progression. The vaccine even seemed to increase HIV transmission rates in those Ad5-seropositive vaccine recipients that had high Ad5-specific antibody titres ${ }^{3,30}$, a result that was not anticipated from studies in rhesus macaques.

The rhesus macaque model has so far been used extensively in the development of HIV vaccines as a surrogate for studying human HIV infection ${ }^{5,6}$. However, the extent of our knowledge about rhesus macaque models is questionable. This Review examines what we can learn from previous studies of human disease in rhesus macaques and how we can best use the non-human primate model in the context of preclinical development for human HIV vaccine trials.

\section{Rhesus macaques and the study of human disease} Rhesus macaques are Old World monkeys that diverged approximately 25 million years ago from the lineage that led to both chimpanzees and humans. Owing to their relative genetic and physiological similarities to humans and their extensive availability, rhesus macaques are the most widely used non-human primates in basic and applied research ${ }^{31}$. However, despite their evolutionary links with humans, there are significant differences that may be relevant to the study of human disease (TABLE 1). For example, the composition of the bacterial flora in the gut $^{32}$ differs between rhesus macaques and humans and may have a significant influence on mucosal immunology patterns, which are important when considering vaccines delivered to mucosal sites, such as live attenuated vectors that are administered orally. Furthermore, differences in the biology at subcutaneous vaccination sites may affect vaccine-specific immunity: the distribution and composition of muscle fibres, the prevalence of interstitial and intra-tissue fat and tissue vascularization can directly influence vaccine distribution, diffusion of the formulation, its rate of clearance and the types of host cell encountered. Differences in these variables could contribute to the difference in immune responses induced by various vaccines between rhesus macaques and humans.

Although rhesus macaques have proved to be invaluable in the study of some human diseases, they are an imperfect system for the study of others. For example, the human teratogen thalidomide (Thalomid; Celgene) does not induce birth defects when administered orally to pregnant rhesus macaques ${ }^{33}$. In addition, rhesus macaques have been suggested as a potential animal model for asthma owing to their development of a human-like asthma phenotype and their responsiveness to some human anti-asthma drugs; however, the experimental anti-asthma drugs developed in the rhesus macaque asthma model were ineffective in treating the human disease $\mathrm{e}^{34-36}$. As discussed elsewhere ${ }^{36}$, "the problem with animal models of asthma is that it is possible to obtain evidence for almost any theory, simply 


\section{Table 1 | Species-specific attributes affecting immunity}

\begin{tabular}{|c|c|c|}
\hline Attribute & Rhesus macaque & Human \\
\hline \multicolumn{3}{|c|}{ Psychosocial or physiological } \\
\hline Typical lifestyle & Active & Sedentary \\
\hline Lifespan & 25 years & $>75$ years (United States) \\
\hline Body mass & $5-8 \mathrm{~kg}$ & $54-76 \mathrm{~kg}$ \\
\hline Diet $^{\star}$ & Non-atherogenic & Atherogenic \\
\hline \multicolumn{3}{|l|}{ Genetic } \\
\hline Diversity & Mainly of Chinese and Indian origin & Global \\
\hline MHC class I loci & $\begin{array}{l}\text { - } 22 \text { active genes or haplotypes } \\
\text { - No equivalent to HLA-C } \\
\text { - Controller haplotypes: Mamu-B08 } \\
\text { and Mamu-B03 }\left(>50 \%^{\ddagger}\right) \text { and } \\
\text { Mamu-B17 }\left(>20 \%^{\ddagger}\right)\end{array}$ & $\begin{array}{l}\text { - } 6 \text { active genes or haplotypes } \\
\text { - HLA-C } \\
\text { - Controller haplotypes: } \\
\text { HLA-B57 and HLA-B27 } \\
\left(<2 \%^{\ddagger}\right)\end{array}$ \\
\hline $\begin{array}{l}\text { MHC class II } \\
\text { loci }\end{array}$ & $\begin{array}{l}\text { More Mamu-DRB genes than in } \\
\text { humans }\end{array}$ & $\begin{array}{l}\text { Fewer HLA-DRB genes than } \\
\text { in rhesus macaques }\end{array}$ \\
\hline
\end{tabular}

by choosing the appropriate conditions. The only way to be sure that a particular model is predictive for clinical asthma is to know the answer in advance and adjust the conditions accordingly to ensure the appropriate results." Furthermore, disease-related genes are different in the two species; for example the genes associated with phenylketonuria and cystic fibrosis in humans are not related to disease in rhesus macaques. Indeed there are fewer cancer-related genes and more immune system genes, including MHC copy numbers ${ }^{37}$ and immunoglobulin $\lambda$-like gene clusters, in rhesus macaques than in humans $s^{38}$ (TABLE 1). So, it is important to remain cautious when interpreting data generated in the rhesus macaque models in the absence of known human disease mechanisms.

Human vaccine research has been affected by incorrect scientific assumptions about the relative importance of a particular primate infection model. For example, studies using rhesus macaques as a model for poliovirus by Simon Flexner in the early 1900s impeded the development of a poliovirus vaccine ${ }^{39}$. Flexner was the laboratory director of the Rockefeller Institute for Medical Research in New York from 1863 to 1946 and a leading expert in pathology and bacteriology. He was considered to be the most prominent poliovirus researcher during this period and renowned for his research on cerebrospinal meningitis, poliovirus and infantile paralysis. Both his choice of the rhesus macaque model and his method of inducing the disease in these animals had unforeseen consequences ${ }^{40}$. Flexner injected poliovirus directly into the brain or spine of rhesus macaques, as well as intranasally, and observed neurovirulent disease and paralysis similar or identical to symptoms of human polio. The virus replicated at high levels in the nervous system, but no blood stage of viral replication was detected. Flexner and colleagues therefore concluded that the mechanism for poliovirus transmission in humans was via a direct route to the brain, probably by infection of the nasal mucosa. This interpretation influenced both public health strategies and vaccine approaches against polio. However, at the time it was unknown that the rhesus macaque, unlike the cynomolgus macaque (Macaca fascicularis), is one of the rare monkeys in which poliovirus does not replicate in the digestive tract and subsequently does not cause an orally acquired infection. Unfortunately, Flexner's conclusions that vaccines may be impossible to develop owing to the absence of a blood replication stage for poliovirus and that vaccine candidates should be grown only in neural cell lines, ideas that were widely embraced by the poliovirus research field, delayed the development of an effective poliovirus vaccine by as many as 40 years. Thus, this interpretation from the rhesus macaque model system shows that scientific assumptions of the importance of a particular primate infection model, based on the manifestation of similar disease symptoms and in the absence of known human correlates, may be ultimately misleading ${ }^{41}$.

Owing to nearly 25 million years of evolution, the abundance and degree of polymorphism of MHC genes have diverged significantly between humans and rhesus macaques ${ }^{37,38}$ (TABLE 1). Currently, we do not fully appreciate the contribution of rhesus macaque MHC molecules to the induction of immunity, especially as an increased ability to recognize and respond to vaccine antigen may directly affect the quality of the immunological memory ${ }^{42-44}$. For example the presence of MHC haplotypes that correlate with viral control seems to affect the outcome of HIV and SIV infection ${ }^{45}$. The increased expression of MHC genes in rhesus macaques might boost their ability to spontaneously control virus as the rhesus macaque MHC class I alleles Mamu-B08 and Mamu-B03, and Mamu-B17 are associated with control of over $50 \%$ and $20 \%$ of cases of SIV ${ }^{46,47}$, respectively, whereas most (>98\%) humans expressing HLA-B57 and HLA-B27 (HLA allele haplotypes linked with virus control in some people) do not control HIV infection (M. Connors, personal communication). Therefore, it is probable that species-specific differences in immune gene expression have an important role in disease outcome and therefore the study of vaccines.

The fact that vaccine-induced $\mathrm{T}$ cell immunity can be more readily achieved in rhesus macaques than in humans might also be related to the anecdotal observation that $\mathrm{T}$ cell responses in rhesus macaques seem to be larger and broader than those induced in humans by identical vaccine preparations. Such differences may be advantageous when carrying out immunoassays that would otherwise fall below the limit of detection, but may also cause undue optimism when evaluating a candidate $\mathrm{T}$ cell vaccine in rhesus macaques. Historically, this has been the case in most clinical trials assessing vaccinespecific T cell-mediated responses (TABLE 2). For example, HIV DNA vaccines in humans induced response rates that were significantly lower than those observed in rhesus macaques: Gag-expressing Ad5-based vaccines induced responses to only a few epitopes in humans whereas responses to more epitopes were induced by the same vaccines in rhesus macaques. With regard to the use of animal models for vaccine development, it could be said that 'mice lie and monkeys exaggerate'. 


\section{Table 2 | Immunogenicity of select cytotoxic T lymphocyte-based vaccines and microbicides against HIV}

\begin{tabular}{|c|c|c|c|c|c|c|c|}
\hline \multirow[t]{2}{*}{ Approach } & \multirow{2}{*}{$\begin{array}{l}\text { Vaccine name or } \\
\text { manufacturer }\end{array}$} & \multirow{2}{*}{$\begin{array}{l}\text { Clinical trial } \\
\text { identification code }\end{array}$} & \multirow{2}{*}{$\begin{array}{l}\text { Phase of } \\
\text { clinical trial }\end{array}$} & \multirow{2}{*}{$\begin{array}{l}\text { Challenge } \\
\text { virus }\end{array}$} & \multicolumn{2}{|c|}{ Response $^{\star}$; efficacy rate ${ }^{\ddagger}(\%)$} & \multirow[t]{2}{*}{ Refs } \\
\hline & & & & & Rhesus macaques & Humans & \\
\hline \multicolumn{8}{|l|}{ Vaccines } \\
\hline VEE virus vector & AVX101/AlphaVax & HVTN040 & 1 & SHIV162P4 & $100 ; 100$ & $0 ; N D$ & 115 \\
\hline Multi-epitope DNA & Epimmune & HVTN048 & 1 & ND & 100; ND & 10; ND & $116-118$ \\
\hline $\begin{array}{l}\text { Multi-epitope } \\
\text { peptides }\end{array}$ & Wyeth & HVTN056 & 1 & SHIVKU2 & $100 ; 84$ & 8; ND & 119,120 \\
\hline Adenovirus vector & STEP/Merck \& Co. & HVTN502/MRK023 & $\|$ & SHIV89.6p & $100 ; 100$ & $62 ; 0^{\S}$ & $121-123$ \\
\hline $\begin{array}{l}\text { Canary poxvirus } \\
\text { vector (ALVAC) }\end{array}$ & Sanofi Pasteur & HVTN039 & 1 & $\begin{array}{l}\text { SHIVKU2 and } \\
\text { SIVmac251 }\end{array}$ & $100 ; 100$ & 10; ND & 124,125 \\
\hline $\begin{array}{l}\text { Canary poxvirus } \\
\text { vector and } \\
\text { lipopeptides }\end{array}$ & ALVAC-HIV/ANRS & $\begin{array}{l}\text { HVTN041/ } \\
\text { ANRSVAC19 }\end{array}$ & 1 & SIVmac251 & $100 ; 13$ & $4 ; \mathrm{ND}$ & 126 \\
\hline DNA plasmid & Wyeth & HVTN060 & I & SHIV89.6p & $100 ; 100$ & 40; ND & 131 \\
\hline $\begin{array}{l}\text { DNA plasmid and } \\
\text { adenovirus vector }\end{array}$ & PAVE 100/VRC & HVTN204 & $\|$ & SIVmac251 & $100 ; 100$ & $70 ; 0$ & 127 \\
\hline $\begin{array}{l}\text { DNA plasmid and } \\
\text { MVA vectors }\end{array}$ & Geovax & HVTN205 & II (ongoing) & SHIV89.6p & $100 ; 100$ & $42 ; 0$ & 23,128 \\
\hline \multicolumn{8}{|l|}{ Microbicides } \\
\hline Nonoxynol-9 & HPTN & HIVNET016 & III & SHIV89.6p & Safe; 50-75 & Safe; $0^{\S}$ & $49-51,129$ \\
\hline Cellulose sulphate & $\begin{array}{l}\text { Family Health } \\
\text { International }\end{array}$ & NCT00120770 & III & R5/X4 SHIV & Safe; 100 & Safe; $0^{\S}$ & 52 \\
\hline Pro2000 & HPTN & HPTN035 & II (ongoing) & SHIV89.6p & Safe; 75 & Safe; 30 & 129,130 \\
\hline
\end{tabular}

*The percentage of individuals responding to vaccination as measured by enzyme-linked immunosorbent spot assay. ${ }^{*}$ The percentage of individuals exhibiting some measurable level of protection against virus transmission or delay in disease progression. ${ }^{\S} \mathrm{HIV}$ transmission increased. MVA, modified vaccinia virus Ankara; ND, not determined; SHIV, HIV Env-expressing SIV; SIV, simian immunodeficiency virus; VEE, Venezuelan equine encephalitis; VRC, Vaccine Research Centre.

An 'exaggerated' immune response was observed in monkeys during the study of specific topical virustatic microbicides. These compounds, which are topically applied inside the vagina or rectum, are designed to provide an additional limitation to the transmission of sexual infections beyond vaccination ${ }^{48}$. Promising results from preclinical challenge studies in rhesus macaques supported the clinical development of such compounds but have correlated poorly with the outcome of clinical trials, for example those of nonoxynol-9 (REFS 49-51) and cellulose sulphate $^{52}$ (TABLE 2). In fact, reminiscent of the results of the STEP trial, use of these compounds increased the incidence of viral transmission in the clinic, a result never observed in the preclinical macaque model ${ }^{49,50,52-55}$.

SIV biology in a non-natural host may account for some of the discrepancies observed between rhesus macaque and clinical data. Sexual transmission of SIV is thought to be the predominant avenue in natural hosts, but it has been difficult to show this in experimentally infected rhesus macaques; a single report has described the potential sexual transmission from female to male pigtailed macaques (Macaca nemestrina) of SIVmne ${ }^{56}$. Sexual transmission of SIV in rhesus macaques does not occur despite detection of virus in all levels of the male reproductive tract ${ }^{57}$. This is unusual as SIV is known to infect stratified squamous cells in the mucosal epithelium of the foreskin and glans of the penis ${ }^{57}$, in which $\mathrm{CD} 4^{+}$Langerhans cells are abundant ${ }^{58}$. Risk behaviour is significantly different between the two species and coitus in rhesus macaques is very brief, whereas human sexual activity can be longer in duration, higher in frequency and more irritating to the genital mucosa, all of which may enhance the transmission of HIV ${ }^{59,60}$. Furthermore, marked differences in the kinetics of HIV and SIV replication may also account for the differences between the data obtained from the rhesus macaque model and human disease $^{61-67}$ (FIG. 1). The importance of circumcision in HIV transmission further complicates the rhesus macaque challenge models. Thus, when using experimental SIV infection in non-natural rhesus macaque hosts as a model for studying HIV vaccines and disease in humans, we must also acknowledge the key differences in viral biology that may contribute to disease outcomes in vaccine settings. Given the apparent failure of rhesus macaques to emulate human disease patterns, we next review how the data generated in rhesus macaques have overwhelmingly attained gatekeeper status in HIV vaccine studies.

\section{Gatekeepers for HIV clinical trials}

Traditionally, preference for the use of non-human primate models for studying human disease was based on several characteristics, including the recapitulation of human disease or its pathology, genetic similarities and the availability of the animal for such studies. In the case of HIV, there was an initial reluctance to give the data generated in non-human primate models any gatekeeper status in the vaccine testing pathway out of concern that potentially effective vaccine candidates might thereby be 


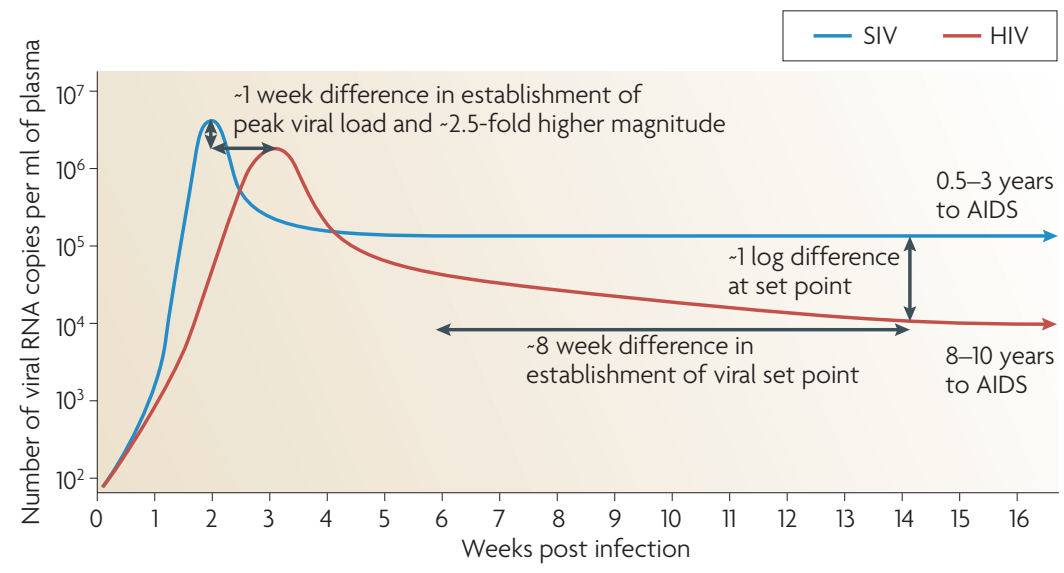

Figure 1 | Viral kinetics of SIV in rhesus macaques and HIV in humans. Typical viral kinetics of simian immunodeficiency virus (SIV) in rhesus macaques ${ }^{66,67}$ and HIV in humans ${ }^{62,64,65}$. Whether SIVmac239, SIVmac251 or SIVsmE660 (SIV from sooty mangabeys) is administered in a high dose intravenously or repeated low doses at a mucosal site, peak viral loads occur approximately 1 week earlier in rhesus macaques than for HIV in humans, and the viral loads are on average 2.5 -fold greater in magnitude but may be lower following a low-dose inoculation. The establishment of the HIV viral set point in humans that do not receive therapy occurs approximately 14 weeks or more after infection, whereas the SIV viral set point in rhesus macaques is established by week 6 . The SIV viral set point is typically in the order of 1 log higher than that of HIV in humans, and simian AIDS-like illness occurs after $0.5-3$ years, compared with after $8-10$ years in humans.

missed $^{6}$; particular concerns were the recapitulation of HIV disease in non-human primates and the stringency of experimental challenge models. However, non-human primate models have had an integral role in HIV research and vaccine testing and, owing to the identification of immunogens with increased immunogenicity and the screening out of low-efficacy candidates, they have now become a much higher priority component of preclinical HIV vaccine tests ${ }^{6}$. This is especially significant when considering the cost and regulatory requirements associated with the manufacture of vaccines for clinical trials.

One of the first non-human primate models used to study HIV pathogenesis and vaccines was chimpanzees $^{68}$. Based on the finding that antibodies from the sera of HIV-infected patients could bind gp120 and neutralize HIV in vitro ${ }^{69}$, early vaccine strategies aimed to induce HIV-specific neutralizing antibodies. Indeed, passive immunization with Env-specific antibodies ${ }^{70}$ and early vaccines expressing the HIV Env protein could provide protection in chimpanzees against challenge with HIV ${ }^{12,13,16-19,71-73}$. However, a lack of efficacy of this strategy was shown in the Phase III clinical trial of VaxGen, a recombinant gp 120 envelope protein vaccine that did not induce any protection ${ }^{20,21}$. These discordant results in chimpanzees and humans might have been due to the small diversity of available HIV challenge viruses that could replicate in chimpanzees, and thus might not be a failure of the model to mimic human HIV infection. However, although chimpanzees are genetically more closely related to humans than are rhesus macaques, chimpanzees that have been experimentally infected with HIV-1 to date show low levels of chronic HIV-1 replication and generally do not develop any disease or detectable pathology similar to that of HIV-1-infected humans. Hypotheses that attempt to explain this phenomenon include the absence of chronic immune activation, higher body temperatures in chimpanzees, resistance of monocytes or macrophages to infection with primary HIV isolates, preservation of $\mathrm{CD}^{+}{ }^{+} \mathrm{T}$ helper cell regenerative capacity, the absence of HIV-1-induced autoimmune phenomena, the absence of CTL infiltration and the absence of degenerative changes in lymphoid follicles ${ }^{11,74-78}$. Of note, this lack of disease progression is not a universal phenomenon as a few HIV-1-infected chimpanzees in captivity have been reported to progress to AIDS and SIVcpz (the chimpanzee strain of SIV)-infected chimpanzees in the wild show 10- to 16-fold as high mortality ${ }^{79-81}$. In addition, one viral isolate originating in a chimpanzee with AIDS, HIV- $1_{\mathrm{NC}}{ }^{80,82}$, can induce rapid peripheral $\mathrm{CD}^{+} \mathrm{T}$ cell loss and high levels of virus in the plasma but low virus burden in the peripheral lymph nodes in both previously uninfected and reinfected chimpanzees. So, the protection observed in early chimpanzee studies did not evaluate pathogenic HIV challenge isolates or strains that induce rapid $\mathrm{CD} 4^{+} \mathrm{T}$ cell depletion, such as HIV-1 ${ }_{\mathrm{NC}}$ or wild-type SIVcpz.

It should also be noted that manifestation of clinical disease in successful animal models has not always been relevant for effective vaccine development (TABLE 3); for example, the chimpanzee hepatitis B virus model did not replicate human disease but still provided the basis for successful development of the human vaccine $e^{83}$. However, the failure of the antibody-based vaccine platform in clinical trials and the inability to produce AIDS-like disease in chimpanzees led investigators to consider new non-human primate models of HIV and SIV infection that may be of greater relevance to human disease and clinical outcomes.

The next obvious choice of model was rhesus macaques, as they can be experimentally infected by SIV and they develop an AIDS-like disease ${ }^{84}$. However, the use of SIV, not HIV, was of concern (TABLE 4). Because inactivated SIV vaccines that can elicit neutralizing antibodies failed to protect rhesus macaques from simian $\mathrm{AIDS}^{85}$, their relevance was questioned. New recombinant SHIV chimeric viruses were constructed and were observed to be highly pathogenic, causing a rapid, systemic and complete loss of $\mathrm{CD}^{+} \mathrm{T}$ cells in rhesus macaques $^{86}$. Initially, the SHIV system was greeted with excitement and accepted as an important new in vivo challenge model. However, the rapid onset of disease and death in rhesus macaques caused by the highly pathogenic nature of this virus was markedly different from that produced by either SIV or HIV, which induce more moderate and gradual loss of $\mathrm{CD}^{+} \mathrm{T}$ cells and slower progression to clinical disease ${ }^{87}$. Despite these concerns, pathogenic SHIV (in particular SHIV89.6p) became a standard challenge model that provided data, which was designated a gatekeeper, for the advancement of HIV vaccines into the clinic. Surprisingly, the highly pathogenic SHIV has proved to be more controllable post-challenge by vaccine regimens that are ineffective at limiting SIV challenge $e^{24,27,29,87}$ (TABLE 2). This outcome highlights the troubling possibility that, in rhesus macaques, severity of pathogenesis elicited by the available collection of HIV, 
Table 3 | Use of the rhesus macaque model in the development of human vaccines

\begin{tabular}{|c|c|c|c|c|}
\hline $\begin{array}{l}\text { Infectious agent or } \\
\text { disease }\end{array}$ & $\begin{array}{l}\text { Rhesus macaque } \\
\text { model available }\end{array}$ & $\begin{array}{l}\text { Important preclinical } \\
\text { model }\end{array}$ & $\begin{array}{l}\text { Human pathogen } \\
\text { studied* }^{\star}\end{array}$ & $\begin{array}{l}\text { Licensed } \\
\text { vaccine }\end{array}$ \\
\hline \multicolumn{5}{|l|}{ Global diseases } \\
\hline HIV & Yes & Rhesus macaques & No (have used SIV) & No \\
\hline Influenza virus & Yes & Ferrets & Yes & Yes \\
\hline Hepatitis A virus & Yes & $\begin{array}{l}\text { Chimpanzees, tamarin } \\
\text { monkeys and owl monkeys }\end{array}$ & Yes & Yes \\
\hline Hepatitis B virus & No & Chimpanzees & Yes & Yes \\
\hline Tuberculosis & Yes & Rhesus macaques & Yes & Yes \\
\hline Typhoid fever & No & Humans & Yes & Yes \\
\hline \multicolumn{5}{|l|}{ Childhood diseases } \\
\hline Polio & Yes & Humans & Yes & Yes \\
\hline Diphtheria & No & Horses & Yes $^{\ddagger}$ & Yes \\
\hline Tetanus & Yes & Horses & Yes $^{\ddagger}$ & Yes \\
\hline $\begin{array}{l}\text { Haemophilus influenzae } \\
\text { type B (Hib) }\end{array}$ & No & Mice and rats & Yes & Yes \\
\hline Measles & Yes & Rhesus macaques & Yes & Yes \\
\hline Mumps & No & Humans & Yes & Yes \\
\hline Pertussis & No & Mice & Yes & Yes \\
\hline Rubella & No & Humans & Yes & Yes \\
\hline $\begin{array}{l}\text { Varicella (chickenpox and } \\
\text { shingles) }\end{array}$ & Yes & $\begin{array}{l}\text { Rhesus macaques and African } \\
\text { green monkeys }\end{array}$ & No (have used SVV) & Yes \\
\hline Meningococcal disease & No & Mice and rats & $Y_{e s}^{\S}$ & Yes \\
\hline Pneumococcal disease & Yes & Rhesus macaques & Yes & Yes \\
\hline Rotavirus & Yes & Mice & Yes & Yes \\
\hline \multicolumn{5}{|l|}{ Tropical diseases } \\
\hline Yellow fever & Yes & Rhesus macaques & Yes & Yes \\
\hline Japanese encephalitis & Yes & Rhesus macaques and mice & Yes & Yes \\
\hline \multicolumn{5}{|c|}{ Potential bioterrorism agents } \\
\hline Smallpox & No & Humans & Yes & Yes \\
\hline Rabies & Yes & Dogs, mice and rabbits & Yes & Yes \\
\hline Anthrax & Yes & Rhesus macaques & Yes & Yes \\
\hline \multicolumn{5}{|l|}{ Other infectious diseases } \\
\hline $\begin{array}{l}\text { Cervical cancer } \\
\text { (papillomavirus) }\end{array}$ & Yes & Rabbits & $\begin{array}{l}\text { No (have used } \\
\text { CRPV) }\end{array}$ & Yes \\
\hline Lyme disease & Yes & Mice, rats and dogs & Yes & Yes \\
\hline
\end{tabular}

*Manifestation of complete human clinical disease in preclinical animal models is extremely rare and has not been a prerequisite for vaccine development. ${ }^{\ddagger}$ Toxoid made from toxin of human pathogen. ${ }^{\S}$ Human pathogen plus transferrin. CRPV, cottontail rabbit papillomavirus; SIV, simian immunodeficiency virus; SVV, simian varicella virus.

SHIV and SIV viruses may not correlate with vaccine efficacy in humans, and that pathogenesis is not linked to the establishment of infection, the ultimate goal in vaccine development.

The Merck \& Co. HIV vaccine that was tested in the STEP trial used a replication-incompetent Ad5-based vector transduced to express HIV proteins. Adenoviruses are non-enveloped, icosahedral viruses that are composed of a double-stranded linear genome and that infect many avian and mammalian species; more than 50 serotypes of human adenoviruses have been identified. Because of their efficient nuclear entry mechanism, ability to infect both non-dividing and dividing cells, low pathogenicity and robust transgene expression, human adenovirus-based vectors have been widely used for the transduction of various cell types in basic research, in gene therapy applications and in vaccine development ${ }^{88}$. Rhesus macaques were used to develop the Ad5-based vaccines, which established the validity of the CTL hypothesis for CTL-based vaccines (that is, that a vaccine inducing HIV-specific CTL responses will protect from disease progression by reducing virus replication) in a primate model. These vaccines were produced in collaboration with and supported by many of the most 
Table 4 | Comparison of SIVmac and HIV-1

\begin{tabular}{|c|c|c|}
\hline Parameter & SIVmac & HIV-1 \\
\hline \multicolumn{3}{|l|}{ Genome } \\
\hline Size & $9.6 \mathrm{~kb}$ & $9.2 \mathrm{~kb}$ \\
\hline Homology to HIV-1* & $55 \%$ & NA \\
\hline Similar genes & \multicolumn{2}{|c|}{ gag, pol, vif, vpr, tat, rev, env and nef } \\
\hline Dissimilar genes & $v p x$ & vpu \\
\hline \multicolumn{3}{|l|}{ Proteins } \\
\hline Homology to HIV-1 & $40-50 \%$ & NA \\
\hline Tat LTR & $\begin{array}{l}44 \text { amino acids longer } \\
\text { than HIV }\end{array}$ & NA \\
\hline Transmembrane protein & Gp32 & Gp41 \\
\hline \multicolumn{3}{|l|}{ Tropism } \\
\hline Host & Rhesus macaques & Humans \\
\hline Main cellular targets & $\mathrm{CD}^{+}{ }^{+} \mathrm{T}$ cells & $\begin{array}{l}\mathrm{CD} 4^{+} \mathrm{T} \text { cells, macrophages } \\
\text { and dendritic cells }\end{array}$ \\
\hline Co-receptor usage & CCR5 & CCR5, CXCR4 and DC-SIGN \\
\hline \multicolumn{3}{|l|}{ Immune factors } \\
\hline Neutralization sensitivity & Resistant & Sensitive \\
\hline Restriction factors & $\begin{array}{l}\text { Resistant to rhesus } \\
\text { macaque TRIM5 } a \text { and } \\
\text { APOBEC } 3 G\end{array}$ & $\begin{array}{l}\text { Sensitive to rhesus macaque } \\
\text { TRIM5 } \alpha \text { and APOBEC3G }\end{array}$ \\
\hline \multicolumn{3}{|l|}{ Transmission } \\
\hline Mother to child & No & Yes \\
\hline Main route & Non-sexual & Sexual \\
\hline
\end{tabular}

prominent academic laboratories working on primate SIV and SHIV. Results from preclinical studies using the rhesus macaque model of Ad5-based vaccination with SHIV challenge supported the advancement of the vaccine into larger clinical trials ${ }^{22,25}$, despite the vaccine's lack of efficacy against SIVmac239 challenges $^{26}$. In the SHIV89.6p model, vaccination could reduce viral load after acquisition of infection, lower $\mathrm{CD} 4^{+} \mathrm{T}$ cell loss and decrease or prevent disease progression ${ }^{22}$; however, as discussed above the vaccine failed to provide protection and possibly enhanced HIV transmission in the STEP clinical trial (TABLE 2).

User-defined quantifiable criteria that can be measured using standardized or validated assays. These criteria should be available before

advancement into clinical trials to allow for thorough understanding of the defined value of a particular vaccine.

Enzyme-linked immunosorbent spot (ELISPOT) assay

A method based on antibody capture for assessing of the numbers of $\mathrm{CD} 4^{+}$and $\mathrm{CD} 8^{+}$ $T$ cells that secrete a particular cytokine (often interferon- $\gamma$ ). inappropriate to blame the use of rhesus macaques in those preclinical studies for the failure in clinical trials - only the interpretation of the result showing protection in that particular challenge model as a gatekeeper. Perhaps the main implication of the STEP trial is that vaccines that protect rhesus macaques against specific SHIV challenge, but not pathogenic SIV, are unlikely to provide protection against HIV infection in humans. Thus, a lack of evidence supporting the major assumptions regarding protection and non-protection in rhesus macaques against SIV challenge suggests that the data generated in rhesus macaque challenge models should not be considered a gatekeeper for early clinical advancement (that is, Phase I clinical trials) until the data can be validated using a predefined immunological correlate in humans (BOX 1).

Rhesus macaques should be used for hypothesisdriven research and the results from immunological screens in these animals can serve as an 'immune gate' for vaccine advancement into Phase I clinical trials. Aside from the known controller MHC haplotypes, in which some individuals spontaneously control the virus ${ }^{45}$, recent evidence in humans suggests that the cytotoxic capacity of HIV-specific CTLs may also correlate with viral control $^{89}$. Therefore, the measurement of interferon- $\gamma$ production by enzyme-linked immunosorbent spot (ELISPOT) assay and the expression of lysis-associated molecules such as perforin and granzymes by flow cytometry, for example, are quantifiable and can be further examined as immune gates for the advancement of candidate vaccines into human immunogenicity studies. Although some of these criteria are met, in part, by current vaccines studied using non-human primates, it remains unclear which effector functions are consistently associated with vaccine-mediated control in the absence of controller MHC haplotypes. And, as mentioned earlier, we should attempt to characterize and avoid, or at least stratify, certain MHC haplotypes in rhesus macaques, as the controller Mamu alleles may or may not be representative of immune-mediated suppression observed among controller MHC haplotypes in humans (TABLE 1). Therefore, more standardized and rigorous approaches that are hypothesis driven, quantifiable and defined by desired clinical end points ${ }^{6}$ should be used during the preclinical testing of vaccine candidates in rhesus macaques. As such, the rhesus macaque model could be effectively used in safety and immunogenicity studies in which advanced screening strategies and not predetermined gatekeeper status could be applied before consideration for the clinic.

The criteria for determining an immune gate in rhesus macaques for the advancement of candidate vaccines into human immunogenicity studies need to be defined. Clearly, the levels of vaccine-induced immune responses, including memory responses, should be greater than prior pre-clinically successful vaccine candidates before advancing to the clinic, and so previous efficacy trials have established a benchmark for future vaccines. If we consider that currently we have no clinically validated CTL-based approach that is more promising than the use of Ad5 in humans, we 


\section{Box 1 | Rhesus macaques in HIV and AIDS research}

The disappointing results from recent clinical trials of candidate HIV vaccines raise questions about the current use of non-human primates and rhesus macaques to generate data used as a 'gatekeeper' for clinical trials. We think that the data from rhesus macaque virus challenge models should not be considered a gatekeeper for the advancement of a vaccine candidate into clinical trials until it can be validated using a predefined immunological correlate of protection in humans. However, data from challenge studies are useful for informational purposes, hypothesis-driven research and the identification of potential immune targets or goals for the clinic.

Instead, immunological data from the rhesus macaque models could be used as 'immune gates' for the advancement of cytotoxic T lymphocyte (CTL)- and antibody-based vaccines into Phase I clinical trials (see the figure). CTL-based vaccines should achieve 'better' CTL responses, in terms of the population size, breadth of epitopes targeted, proliferative capacity, cytokine profile and killing activity, than adenovirus serotype 5 (Ad5)-based vaccines in rhesus macaque studies. The immunological data should also be capable of reaching predefined and quantifiable benchmarks of immune responses, such as the induction of CTLs that can kill infected cells at a predefined level and rate. Antibodybased vaccines should elicit 'useful' titres of neutralizing antibodies (according to a defined neutralization end point and response rate) against a panel of HIV envelope (Env)-expressing viruses, not simian immunodeficiency virus (SIV) Env-expressing viruses, in non-human primates, or other antibody-relevant species.

Clinical trials that test CTL vaccine efficacy should proceed only if predefined human immune criteria are met and if these criteria are better than those met by Ad5-based vaccines in humans.

Research is needed to develop better chimeric, HIV Env-expressing SIV viruses, genome-shuffled HIVs and HIV variants to overcome the problems associated with HIV and SIV divergence, neutralization and resistance.

As the recapitulation of human clinical disease in animal models was not relevant for many model systems used for the development of vaccines against other viruses (TABLE 3), the search for new models using naturally occurring lentiviruses that may or may not mimic HIV disease in humans is important.

know that next-generation CTL vaccines must induce 'better' immune responses than Ad5-based vaccines do in rhesus macaques. But to establish quantifiable benchmarks to serve as immune gates in this model of vaccination, we need to better define the quality of vaccine-induced immunity in rhesus macaques. The STEP trial was initiated based on only a limited amount of immunogenicity data, aside from protection against SHIV challenge, such as the magnitude and breadth of virus-specific CTL responses as determined by ELISPOT assays. Many questions remain unanswered: what types of $\mathrm{T}$ cell memory phenotypes are generated? How polyfunctional are the memory $\mathrm{T}$ cells? Do they exhibit proliferative capacity? Do they have a lytic function? Do they inhibit virus production by target cells? And how do these quantifiable attributes segregate with the different $\mathrm{T}$ cell subsets? Quantifiable immune functions that can be assessed using standard immunoassays should be used to better define benchmarks for the advancement of vaccine candidates from the rhesus macaque model into the clinic.

As for a vaccine-elicited antibody response, we currently have no approach that induces even a modestly broad neutralizing antibody response in humans. The structural features of the HIV Env glycoprotein and its vast variability have frustrated efforts to induce broadly reactive neutralizing antibodies. However, the contribution of antibodies to protection still remains controversial. Recent studies show that HIV-infected humans who do generate highly crossreactive, broad neutralizing antibody responses can still become super-infected by a second strain of $\mathrm{HIV}^{90}$, suggesting that infection can occur even in the presence of HIV-specific neutralizing antibodies. Furthermore, evidence in rhesus macaques suggests that T cell-based vaccines, when not expressing the Env protein and in the absence of Env-specific antibodies, may have a greater potential than otherwise thought in protecting against a challenge with SIVsmE660 (sooty mangabey SIV E660) ${ }^{91}$. Although the role of broadly neutralizing antibodies in protecting against virus transmission remains unclear, they should continue to be an important goal of next-generation HIV vaccines - especially because cell-free virus, and not cell-associated virus, was recently reported in a conference abstract ${ }^{92}$ to be the major source of transmitting virus, suggesting a potentially important role for broadly neutralizing antibodies at mucosal sites. Also, recent studies in rhesus macaques show a correlation between neutralizing antibodies and protection against challenge with a particularly neutralization-sensitive strain of SIV, SIVmac316 (REF. 93). However, convincing antibody data generated in rabbits and other large animal species, which could include non-human primates, showing greater breadth of neutralization must be shown for new antibody approaches to be advanced into Phase I clinical trials (BOX 1). Thus, data can be generated in rhesus macaques or other relevant antibody-producing species without the requirement for protection against SIV or SHIV challenge, which are encouraged for informational purposes to guide future vaccine development. 
In light of the STEP trial, the data from rhesus macaque challenge models should not be used as a gatekeeper for Phase I clinical trials, and should be used only for hypothesis-driven basic research until a widely accepted challenge model in rhesus macaques has been validated using a known correlate of protection in humans. A few vaccination strategies have limited the progression to simian AIDS in macaques challenged with highly pathogenic SIVmac, such as SIVmac239 and the heterologous swarm viruses SIVmac251 and SIVsmE660 (REF. 94), which suggests that their use might provide a more rigorous model for clinical vaccine candidates. However, the current use of various SIV isolates and the techniques in which they are administered to mimic HIV transmission and pathogenesis remain controversial. Virus stocks remain too variable and diverse, and outcomes from the same challenges can differ, the reasons for which are not yet understood. There is little data available to address these issues, most of the data comes from studies of SIV infection in rhesus macaques that have been carried out by intravenous inoculation with the strains SIVmac239 and SIVmac251 (REF. 5), which both use CD4 and CC-chemokine receptor 5 (CCR5) for entry to host cells ${ }^{95-97}$ and cause acute infections characterized by cell-associated and cell-free viraemia. However, high doses of these viruses are typically used to ensure infection, and this practice may overwhelm a potential vaccine response and does not accurately represent the low dose of virus that is associated with natural HIV transmission, which seems to be in the order of one to five transmitted or founder viruses ${ }^{98,99}$.

It is currently thought that experimental transmission should replicate natural invasion through the mucosa, using such inoculation techniques as low-dose mucosal challenge $\mathrm{e}^{100}$. This method of virus delivery to rhesus macaques may be a more useful challenge model for evaluating hypothesis-driven research, as the transmission of low numbers of founder viruses may better mimic natural transmission in humans. However, it is possible that by using low-dose repeated challenge we are setting the bar too low because in monkeys that are kept in otherwise pathogen-free conditions, and in the absence of co-factors that may influence the acquisition of and course of infection, we may see protection that could then disappear in humans harbouring local co-infections. Also, this approach is logistically challenging and expensive as more animals are required per group because a productive infection is not always achieved in every animal. But, improvements to mucosal inoculation techniques will undoubtedly enhance their efficacy and utility and may one day include the addition of co-factors such as pro-inflammatory mediators or microbial co-infection. Thus, low-dose repeated challenge as an administration technique to deliver clinically relevant isolates of SIV may offer a more physiologically relevant regimen for pathogenic SIV challenge experiments ${ }^{100}$, until an accepted challenge model based on known human correlates can be established.

A greater diversity of challenge isolates in the future may help to better mimic human AIDS in the rhesus macaque model. The SIVsmE660 and SIVmac viruses are currently the challenge viruses of choice, and there are notable differences between these viruses and HIV. For example, their genomes have only a $55 \%$ sequence homology with that of HIV-1 whereas they have a $\sim 75 \%$ sequence homology with that of HIV-2 and a 54-84\% sequence homology with SHIVs (FIG. 2). This moderate level of homology to HIV-1 is also observed for the unrelated retrovirus Moloney murine leukaemia retrovirus (44\% sequence homology). In addition, the replication rates, establishment of chronic viral set point and manifestation of AIDS significantly differ between the SIVs and HIV in their respective hosts ${ }^{101-107}$ (FIG. 1). It is probable that viruses that are generated to have greater homology with HIV and that retain the ability to cause AIDS-like disease could be more useful for rhesus macaque challenge studies than current SIV or SHIV viruses ${ }^{4}$.

\begin{tabular}{|c|c|c|c|c|c|c|c|c|c|c|}
\hline \multirow{8}{*}{ HIV- $]^{\ddagger}$} & SIVcpz & SHIV89.6p & SIVsmm & SIVmne027 & SIVmac239* & SIVmac251* & SIVagm & HIV-2 & SIVsmE660 & MMLV \\
\hline & 72.8 & 67.5 & 56.9 & 56.8 & 56.8 & 56.6 & 56.6 & 55.8 & 52.1 & 44.4 \\
\hline & SIVcpz & 60.8 & 56.6 & 56.8 & 56.6 & 56.9 & 56.9 & 56.4 & 50.5 & 44.6 \\
\hline & & SHIV89.6p & 76.0 & 83.1 & 84.5 & 84.0 & 56.1 & 69.9 & 54.1 & 44.5 \\
\hline & & & SIVsmm & 85.6 & 84.3 & 84.7 & 58.7 & 76.5 & 92.5 & 45.0 \\
\hline & & & & SIVmne027 & 95.7 & 95.8 & 58.5 & 76.6 & 83.3 & 44.9 \\
\hline & & & & & SIVmac239 & 97.7 & 58.6 & 75.7 & 82.5 & 43.8 \\
\hline & & & & & & SIVmac251 & 58.4 & 75.9 & 82.5 & 44.9 \\
\hline$\geq 40 \%$ & & $\geq 70 \%$ & & & & & SIVagm & 58.6 & 56.5 & 45.1 \\
\hline$\geq 50 \%$ & & $\geq 80 \%$ & & & & & & HIV-2 & 76.2 & 44.6 \\
\hline$\geq 60 \%$ & & $\geq 90 \%$ & & & & & & & SIVsmE660 & 47.4 \\
\hline
\end{tabular}

Figure 2 | Genome homology of select Retroviridae. Genome sequence homology among select Retroviridae based on published data deposited in GenBank (HIV-1: NC_001802; SIVcpz: AF115393; SHIV89.6p: SIU89134; SIVsmm, clone PBj6.6: L09212; SIVmne027: SIU79412; SIVmac239: AY588945; SIVmac251, isolate Mm251: M19499; SIVagm, circular replicative intermediate DNA: X07805; HIV-2: NC_001722; SIVsmE660, isolate, TB1L partial: FJ579055; Moloney murine leukaemia virus (MMLV): NC_001,501). *Pathogenic in rhesus macaques; ${ }^{\ddagger}$ pathogenic in humans. SHIV, HIV Env-expressing SIV; SIV, simian immunodeficiency virus. 
Antiretroviral restriction factors

Host factors, including the TRIM and APOBEC proteins, that function to limit retroviral infection. For example, TRIM5a recognizes motifs in viral capsid proteins and interferes with the uncoating process. APOBEC proteins inhibit retroviruses by deaminating cytosine residues in retroviral cDNA. To

counteract this cellular defence, HIV encodes Vif, which mediates APOBEC degradation. Retroviral restriction by these factors is species specific and therefore is a crucial determinant of tropism of retroviral infection.
A better understanding of the key genetic and structural differences between the SIV and HIV viruses may help to guide the development of next-generation challenge models and/or chimeric virus strains that may better mimic HIV infection and disease pathology in humans. Recombinant simian-tropic HIVs have been generated that evade the antiretroviral restriction factors TRIM5a (tripartite motif-containing 5a) and $\mathrm{APOBEC} 3 \mathrm{G}$ (apolipoprotein B mRNA-editing enzyme, catalytic polypeptide-like $3 \mathrm{G}$ ) by replacing HIV capsid and Vif sequences with the sequences that effectively evade simian TRIM5 $\alpha$ and APOBEC3G and this increases the infectivity of the virus in rhesus macaques ${ }^{108-110}$, but these virus variants have yet to be shown to replicate at high levels and result in HIV-like disease in rhesus macaques. In fact, high levels of virus replication even in the absence of disease may be a valuable vaccine model, as is the case for hepatitis B virus infection of chimpanzees. Also, because SHIVs are more homologous to HIV-1 than is SIV, the development of new virus strains that mimic HIV disease but are resistant to treatments that protect against firstgeneration SHIVs may prove useful for vaccine evaluation $^{111}$. Although attempts to generate more HIV-like SHIVs have failed so far ${ }^{112,113}$, a better understanding of the interactions between the virus and the host cell may help to identify key viral proteins and/or their specific structural regions that are required for replication of HIV in non-human primates. Such a development may help the challenge model to better resemble those preclinical rhesus macaque models that successfully used a human pathogen for vaccine studies and licensure (TABLE 3); out of the 24 vaccines currently licensed in the United States, $40 \%$ were successfully developed using non-human primates but only $11 \%$ of those effectively used a simian virus instead of the human pathogen as a model. Therefore, we should certainly not dismiss the use of current rhesus macaque challenge models for vaccine research. It is important that new hypotheses based on the outcome of challenge studies are generated, as these can drive the development and clinical testing based on new benchmarks.

In summary, Phase I clinical trials of candidate HIV vaccines evaluating safety and predefined immune correlates are crucial for the advancement of HIV studies but should not be continued to efficacy trials unless the vaccine's immunogenicity is shown to be better than that of Ad5-based vaccines in humans. This is a crucial goal for HIV vaccine development that should be considered independently from SIV and SHIV challenge models owing to the fact there is limited evidence that protection in rhesus macaques equates to protection in humans (BOX 1). So, approaches that are advanced to clinical trials must produce better immune responses in rhesus macaques in standardized and quantifiable immunogenicity experiments than approaches tested in clinical trials so far. Nevertheless, to study vaccine candidates in the clinical setting, it is still useful to examine them in current SIV challenge models, as the information generated from these studies can guide future vaccine development.

\section{Concluding remarks}

The road to an HIV vaccine using the non-human primate model has been turbulent and controversial and has met with far fewer instances of success than failure. Both of the two human HIV vaccine efficacy trials conducted to date have failed. But we must not let this stop us from moving forward. Despite the many limiting factors surrounding the use of non-human primates in preclinical research, rhesus macaques have made countless contributions to the understanding, treatment and prevention of human disease (TABLE 3). We must proceed in the fight against HIV and AIDS using the best animal model possible in a responsible, hypothesis-driven and ethical manner. Data from the rhesus macaque model must be critically evaluated to maximize the rational design of HIV vaccines and to ensure their safety and immunogenicity when moved into clinical trials. Advanced screening strategies using predefined immune gates in preclinical studies should be designed to eliminate suboptimal vaccine candidates early in the testing process. Before clinical trial advancement there should be immune response data in nonhuman primates ${ }^{6}$ (BOX 1). An HIV vaccine approach that moves forward in the clinic should continue to be studied in validated macaque models in which information on outcomes, as well as further definition of immune phenotype, is obtained. Gatekeeper status cannot be assigned to a particular challenge model until a known correlate in humans is defined. However, primate studies can function as immune gates to identify new vaccines and to define new immune gates that show a level of improvement over prior non-successful vaccine candidates for clinical evaluation. Thus, we need to remain cautious when using animal models in experimentation, critical during the interpretation of data and vigilant in our quest to apply such information to the prevention of human disease. This in mind, we would be wise to heed the words of statistician George E. P. Box: "all models are wrong, but some are useful”114.
1. Thomas, C. Roadblocks in HIV research: five questions. Nature Med. 15, 855-859 (2009).

2. Gardner, M. B. \& Luciw, P. A. Animal models of AIDS. FASEB J. 3, 2593-2606 (1989).

3. Sekaly, R. P. The failed HIV Merck vaccine study: a step back or a launching point for future vaccine development? J. Exp. Med. 205, 7-12 (2008).

4. Ambrose, Z., KewalRamani, V. N., Bieniasz, P. D. \& Hatziioannou, T. HIV/AIDS: in search of an animal model. Trends Biotechnol. 25, 333-337 (2007).

5. Lackner, A. A. \& Veazey, R. S. Current concepts in AIDS pathogenesis: insights from the SIV/macaque model. Annu. Rev. Med. 58, 461-476 (2007).
6. Morgan, C. et al. The use of nonhuman primate models in HIV vaccine development. PLoS Med. 5, e173 (2008)

7. Williams, R. et al. Nonhuman primate models of NeuroAIDS. J. Neurovirol. 14, 292-300 (2008).

8. Baenziger, S. et al. Disseminated and sustained HIV infection in $\mathrm{CD}_{34}{ }^{+}$cord blood cell-transplanted Rag $2^{-/} \gamma \mathrm{c}^{-/-}$mice. Proc. Natl Acad. Sci. USA 103 15951-15956 (2006).

9. Silvestri, G. et al. Nonpathogenic SIV infection of sooty mangabeys is characterized by limited bystander immunopathology despite chronic high-level viremia. Immunity 18, 441-452 (2003).
This report showed that natural hosts for SIV infection such as sooty mangabeys do not develop AIDS despite high levels of virus replication and limited antiviral $\mathrm{CD}^{+}{ }^{+} \mathrm{T}$ cell responses. These animals also exhibit lower levels of immune activation and maintain $\mathrm{CD4}^{+} \mathrm{T}$ cell populations and regenerative capacity.

10 Paiardini, M., Frank, I., Pandrea, I., Apetrei, C. \& Silvestri, G. Mucosal immune dysfunction in AIDS pathogenesis. AIDS Rev. 10, 36-46 (2008).

11. Silvestri, G., Paiardini, M., Pandrea, I., Lederman, M. M. $\&$ Sodora, D. L. Understanding the benign nature of SIV infection in natural hosts. J. Clin. Invest. 117 3148-3154 (2007) 
12. Lubeck, M. D. et al. Long-term protection of chimpanzees against high-dose HIV-1 challenge induced by immunization. Nature Med. 3, 651-658 (1997).

13. Boyer, J. D. et al. Protection of chimpanzees from high-dose heterologous HIV-1 challenge by DNA vaccination. Nature Med. 3, 526-532 (1997). This paper showed the efficacy of an HIV DNA vaccine in protecting chimpanzees from infection with an HIV-1 SF2 virus.

14. Kutzler, M. A. \& Weiner, D. B. DNA vaccines: ready for prime time? Nature Rev. Genet. 9, 776-788 (2008).

15. Wang, B. et al. Gene inoculation generates immune responses against human immunodeficiency virus type 1. Proc. Natl Acad. Sci. USA 90, 4156-4160 (1993).

16. Berman, P. W. et al. Protection of chimpanzees from infection by HIV- 1 after vaccination with recombinant glycoprotein gp 120 but not gp 160. Nature 345 622-625 (1990)

17. Berman, P. W. et al. Protection of MN-rgp120immunized chimpanzees from heterologous infection with a primary isolate of human immunodeficiency virus type 1. J. Infect. Dis. 173, 52-59 (1996).

18. Fultz, P. N. et al. Vaccine protection of chimpanzees against challenge with HIV-1-infected peripheral blood mononuclear cells. Science 256, 1687-1690 (1992).

19. Girard, M. et al. Immunization of chimpanzees confers protection against challenge with human immunodeficiency virus. Proc. Natl Acad. Sci. USA 88, 542-546 (1991).

20. Pitisuttithum, P. et al. Randomized, double-blind, placebo-controlled efficacy trial of a bivalent recombinant glycoprotein 120 HIV-1 vaccine among injection drug users in Bangkok, Thailand. J. Infect. Dis. 194, 1661-1671 (2006)

21. Watanabe, M. E. Skeptical scientists skewer VaxGen statistics. Nature Med. 9, 376 (2003).

22. Shiver, J. W. et al. Replication-incompetent adenoviral vaccine vector elicits effective anti-immunodeficiencyvirus immunity. Nature 415, 331-335 (2002). This report showed the efficacy of replicationincompetent Ad5 vector vaccines in protecting rhesus macaques against SHIV challenge.

23. Amara, R. R. et al. Control of a mucosal challenge and prevention of AIDS by a multiprotein DNA/MVA vaccine. Science 292, 69-74 (2001)

24. Barouch, D. H. et al. Control of viremia and prevention of clinical AIDS in rhesus monkeys by cytokineaugmented DNA vaccination. Science 290, 486-492 (2000).

25. Liang, X. et al. Vectored Gag and Env but not Tat show efficacy against simian-human immunodeficiency virus 89.6P challenge in Mamu-A*01-negative rhesus monkeys. J. Virol. 79, 12321-12331 (2005).

26. Casimiro, D. R. et al. Attenuation of simian immunodeficiency virus SIVmac239 infection by prophylactic immunization with DNA and recombinant adenoviral vaccine vectors expressing Gag. J. Virol. 79, 15547-15555 (2005). This manuscript showed that vaccines providing protection against SHIV challenge did not protect against highly pathogenic SIVmac239 intrarectal challenge.

27. Horton, H. et al. Immunization of rhesus macaques with a DNA prime/modified vaccinia virus Ankara boost regimen induces broad simian immunodeficiency virus (SIV)-specific T-cell responses and reduces initial viral replication but does not prevent disease progression following challenge with pathogenic SIVmac239. J. Virol. 76, 7187-7202 (2002). This report showed that DNA or recombinant viral vector vaccines providing protection against SHIV89.6p challenge did not protect against highly pathogenic SIVmac239 intravenous challenge.

28. Ourmanov, I., Bilska, M., Hirsch, V. M. \& Montefiori, D. C. Recombinant modified vaccinia virus ankara expressing the surface gp120 of simian immunodeficiency virus (SIV) primes for a rapid neutralizing antibody response to SIV infection in macaques. J. Virol. 74, 2960-2965 (2000).

29. Ourmanov, I. et al. Comparative efficacy of recombinant modified vaccinia virus Ankara expressing simian immunodeficiency virus (SIV) Gag-Pol and/or Env in macaques challenged with pathogenic SIV. J. Virol. 74, 2740-2751 (2000).

30. Robb, M. L. Failure of the Merck HIV vaccine: an uncertain step forward. Lancet 372, 1857-1858 (2008).
31. Gardner, M. B. \& Luciw, P. A. Macaque models of human infectious disease. ILAR J. 49, 220-255 (2008)

32. McKenna, P. et al. The macaque gut microbiome in health, lentiviral infection, and chronic enterocolitis. PLoS Pathog. 4, e20 (2008)

33. Scott, W. J., Wilson, J. G. \& Helm, F. C. A metabolite of a structural analog of thalidomide lacks teratogenic effect in pregnant rhesus monkeys. Teratology 22. 183-185 (1980)

34. Turner, $\mathrm{C}$. R et al In vitro and in vivo effects of leukotriene B4 antagonism in a primate model of asthma. J. Clin. Invest. 97, 381-387 (1996).

35. Hogan, M. B., Harris, K. E., Protter, A. A. \& Patterson, R. A bradykinin antagonist inhibits both bradykinin- and the allergen-induced airway response in primates. Proc. Assoc. Am. Physicians 109 269-274 (1997)

36. Coleman, R. A. Current animal models are not predictive for clinical asthma. Pulm. Pharmacol. Ther 12, 87-89 (1999)

37. Daza-Vamenta, R., Glusman, G., Rowen, L., Guthrie, B. $\&$ Geraghty, D. E. Genetic divergence of the rhesus macaque major histocompatibility complex. Genome Res. 14, 1501-1515 (2004)

38. Gibbs, R. A. et al. Evolutionary and biomedical insights from the rhesus macaque genome. Science 316, 222-234 (2007)

This study identified more active immune genes in the rhesus macaque genome than in the human genome.

39. Oshinsky, D. M. Polio: an American Story (Oxford Univ. Press, New York, 2005).

40. Guerrini, A. Experimenting with Humans and Animals: from Galen to Animal Rights (Johns Hopkins Univ. Press, Baltimore, 2003).

41. Horstmann, D. M. The poliomyelitis story: a scientific hegira. Yale J. Biol. Med. 58, 79-90 (1985).

42. Shedlock, D. J. \& Shen, H. Requirement for CD4 T cell help in generating functional CD8 T cell memory. Science 300, 337-339 (2003)

43. Sun, J. C. \& Bevan, M. J. Defective CD8 T cell memory following acute infection without CD4 T cell help. Science 300, 339-342 (2003)

44. Janssen, E. M et al. CD4+ $T$ cells are required for secondary expansion and memory in CD8 ${ }^{+}$ T lymphocytes. Nature 421, 852-856 (2003). This study, together with references 42 and 43 shows that $\mathrm{CD} 4^{+} \mathrm{T}$ cell help during the acute phase of infection is crucial for the generation of functional $\mathrm{CD}^{+} \mathrm{T}$ cell memory.

45. Goulder, P. J. \& Watkins, D. I. Impact of MHC class I diversity on immune control of immunodeficiency virus replication. Nature Rev. Immunol. 8, 619-630 (2008)

46. Hendel, H. et al. New class I and II HLA alleles strongly associated with opposite patterns of progression to AIDS. J. Immunol. 162, 6942-6946 (1999).

47. Lambotte, O. et al. HIV controllers: a homogeneous group of HIV-1-infected patients with spontaneous control of viral replication. Clin. Infect. Dis. 41, 1053-1056 (2005)

48. Lederman, M. M., Jump, R., Pilch-Cooper, H. A Root, M. \& Sieg, S. F. Topical application of entry inhibitors as "virustats" to prevent sexual transmission of HIV infection. Retrovirology 5, 116 (2008)

49. Miller, C. J. et al. Effect of virus dose and nonoxynol-9 on the genital transmission of SIV in rhesus macaques. J. Med. Primatol. 19, 401-409 (1990)

50. Kreiss, J. et al. Efficacy of nonoxynol 9 contraceptive sponge use in preventing heterosexual acquisition of HIV in Nairobi prostitutes. JAMA 268, 477-482 (1992).

51. Van Damme, L. et al. Effectiveness of COL-1492, nonoxynol-9 vaginal gel, on HIV-1 transmission in female sex workers: a randomised controlled trial. Lancet 360, 971-977 (2002).

52. Van Damme, L. et al. Lack of effectiveness of cellulose sulfate gel for the prevention of vaginal HIV transmission. N. Engl. J. Med. 359, 463-472 (2008)

53. Ramjee, G., Govinden, R., Morar, N. S. \& Mbewu, A South Africa's experience of the closure of the cellulose sulphate microbicide trial. PLOS Med. 4 , e235 (2007)

54. Roddy, R. E. et al. A controlled trial of nonoxynol 9 film to reduce male-to-female transmission of sexually transmitted diseases. N. Engl. J. Med. 339, 504-510 (1998).
55. Rustomjee, R., Abdool Karim, Q., Abdool Karim, S. S Laga, M. \& Stein, Z. Phase 1 trial of nonoxynol-9 film among sex workers in South Africa. AIDS 13 1511-1515 (1999)

56. Kuller, L., Benveniste, R. E., Watanabe, R., Tsai, C. C. \& Morton, W. R. Transmission of SIVMne from female to male Macaca nemestrina. J. Med. Primatol. 21, 299-307 (1992)

57. Miller, C. J. Localization of simian immunodeficiency virus-infected cells in the genital tract of male and female Rhesus macaques. J. Reprod. Immunol. 41 331-339 (1998)

58. Miller, C. J. et al. Pathology and localization of simian immunodeficiency virus in the reproductive tract of chronically infected male rhesus macaques. Lab. Invest. 70, 255-262 (1994).

59. Garnett, G. P. $\&$ Rottingen, J. A. Measuring the risk of HIV transmission. AIDS 15, 641-643 (2001).

60. Quinn, T. C. et al. Viral load and heterosexual transmission of human immunodeficiency virus type 1 Rakai Project Study Group. N. Engl. J. Med. 342, 921-929 (2000)

61. Gordon, S. N. et al. Severe depletion of mucosal CD4 $T$ cells in AIDS-free simian immunodeficiency virusinfected sooty mangabeys. J. Immunol. 179 3026-3034 (2007).

62. Little, S. J., McLean, A. R., Spina, C. A., Richman, D. D. \& Havlir, D. V. Viral dynamics of acute HIV-1 infection. J. Exp. Med. 190, 841-850 (1999).

63. Milush, J. M. et al. Virally induced CD4+ T cell depletion is not sufficient to induce AIDS in a natural host. J. Immunol. 179, 3047-3056 (2007).

64. Novitsky, V. et al. Viral load and CD4+ T-cell dynamics in primary HIV-1 subtype C infection. J. Acquir. Immune Defic. Syndr. 50, 65-76 (2009).

65. Stekler, J. et al. HIV dynamics in seminal plasma during primary HIV infection. AIDS Res. Hum. Retroviruses 24, 1269-1274 (2008)

66. Wilson, N. A. et al. Vaccine-induced cellular immune responses reduce plasma viral concentrations after repeated low-dose challenge with pathogenic simian immunodeficiency virus SIVmac239. J. Virol. 80, 5875-5885 (2006).

67. Yeh, W. W. et al. Partial protection of simian immunodeficiency virus (SIV)-infected rhesus monkeys against superinfection with a heterologous SIV isolate. J. Virol. 83, 2686-2696 (2009)

68. Letvin, N. L. \& King, N. W. Immunologic and pathologic manifestations of the infection of rhesus monkeys with simian immunodeficiency virus of macaques. J. Acquir. Immune Defic. Syndr. 3 1023-1040 (1990)

69. Schnittman, S. M. et al. Characterization of GP120 binding to CD4 and an assay that measures ability of sera to inhibit this binding. J. Immunol. 141 4181-4186 (1988)

70. Emini, E. A. et al. Prevention of HIV-1 infection in chimpanzees by gp 120 V3 domain-specific monoclonal antibody. Nature 355, 728-730 (1992).

This report showed the protective efficacy of a neutralizing, V3 domain-specific antibody in chimpanzees against challenge with the HIV IIIb variant.

71. Boyer, J. D. et al. In vivo protective anti-HIV immune responses in non-human primates through DNA immunization. J. Med. Primatol. 25, 242-250 (1996).

72. Bruck, C. et al. HIV-1 envelope-elicited neutralizing antibody titres correlate with protection and virus load in chimpanzees. Vaccine 12, 1141-1148 (1994).

73. Girard, M. et al. Vaccine-induced protection of chimpanzees against infection by a heterologous human immunodeficiency virus type 1. J. Virol. 69 6239-6248 (1995)

74. Estaquier, J. et al. Programmed cell death and AIDS: significance of T-cell apoptosis in pathogenic and nonpathogenic primate lentiviral infections. Proc. Natl Acad. Sci. USA 91, 9431-9435 (1994).

75. Gougeon, M. L. et al. Lack of chronic immune activation in HIV-infected chimpanzees correlates with the resistance of T cells to Fas/Apo-1 (CD95)-induced apoptosis and preservation of a T helper 1 phenotype. J. Immunol. 158, 2964-2976 (1997).

76. Koopman, G., Haaksma, A. G., ten Velden, J., Hack, C. E. \& Heeney, J. L. The relative resistance of HIV type 1 -infected chimpanzees to AIDS correlates with the maintenance of follicular architecture and the absence of infiltration by $\mathrm{CD} 8{ }^{+}$cytotoxic T lymphocytes. AIDS Res. Hum. Retroviruses 15 365-373 (1999). 
77. Schuitemaker, H. et al. Lack of T cell dysfunction and programmed cell death in human immunodeficiency virus type 1 -infected chimpanzees correlates with absence of monocytotropic variants. J. Infect. Dis. 168, 1140-1147 (1993)

78. Zarling, J. M. et al. HIV-infected humans, but not chimpanzees, have circulating cytotoxic T lymphocytes that lyse uninfected $\mathrm{CD}^{+}{ }^{+}$cells. J. Immunol. 144 2992-2998 (1990).

79. Keele, B. F. et al. Increased mortality and AIDS-like immunopathology in wild chimpanzees infected with SIVcpz. Nature 460, 515-519 (2009).

80. Novembre, F. J. et al. Rapid CD4+ T-cell loss induced by human immunodeficiency virus type $1_{\mathrm{NC}}$ in uninfected and previously infected chimpanzees. J. Virol. 75, 1533-1539 (2001)

81. O'Neil, S. P. et al. Progressive infection in a subset of HIV-1-positive chimpanzees. J. Infect. Dis. 182 1051-1062 (2000)

82 Novembre, F. J et al. Development of AIDS in chimpanzee infected with human immunodeficiency virus type 1. J. Virol. 71, 4086-4091 (1997).

83. Maynard, J. E., Berquist, K. R., Krushak, D. H. \& Purcell, R. H. Experimental infection of chimpanzees with the virus of hepatitis B. Nature 237, 514-515 (1972).

84. Miller, C. J. et al. Genital mucosal transmission of simian immunodeficiency virus: animal model for heterosexual transmission of human immunodeficiency virus. J. Virol. 63, 4277-4284 (1989).

85. Sutjipto, S. et al. Inactivated simian immunodeficiency virus vaccine failed to protect rhesus macaques from intravenous or genital mucosal infection but delayed disease in intravenously exposed animals. J. Virol. 64 2290-2297 (1990)

86. Reimann, K. A. et al. A chimeric simian/human immunodeficiency virus expressing a primary patient human immunodeficiency virus type isolate env causes an AIDS-like disease after in vivo passage in rhesus monkeys. J. Virol. 70 6922-6928 (1996)

This manuscript described chimeric SHIV89.6p as a rhesus macaque challenge virus that induced $\mathrm{CD}^{+} \mathrm{T}$ cell depletion and an AIDS-like disease.

87. Nishimura, Y. et al. Highly pathogenic SHIVs and SIVs target different $C D 4^{+} \mathrm{T}$ cell subsets in rhesus monkeys, explaining their divergent clinical courses. Proc. Natl Acad. Sci. USA 101, 12324-12329 (2004).

88. Fields, B. N., Knipe, D. M. \& Howley, P. M. Fields Virology (Wolters Kluwer Health, Philadelphia, 2007).

89. Migueles, S. A. et al. Lytic granule loading of CD8+ $T$ cells is required for HIV-infected cell elimination associated with immune control. Immunity 29 1009-1021 (2008)

This paper showed that HIV-specific CD8 ${ }^{+} \mathrm{T}$ cell control correlated with lytic granule loading and delivery of granzyme B to target cells.

90. Blish, C. A. et al. Human immunodeficiency virus type 1 superinfection occurs despite relatively robust neutralizing antibody responses. J. Virol. 82, 12094-12103 (2008).

91. Wilson, N. A. et al. Vaccine-induced cellular responses control SIV replication after heterologous challenge. J. Virol. 83, 6508-6521 (2009)

92. Butler, D., Lakdawala, M., Richman, D. D., Little, S. J. $\&$ Smith, D. G. Cell-free virus in seminal plasma samples is the origin of sexually transmitted HIV among men who have sex with men.16th Conference on Retroviruses and Opportunistic Infections, Montreal [Online abstract](2009).

93. Johnson, P. R. et al. Vector-mediated gene transfer engenders long-lived neutralizing activity and protection against SIV infection in monkeys. Nature Med. 15, 901-906 (2009).

94. Reynolds, M. R. et al. Macaques vaccinated with liveattenuated SIV control replication of heterologous virus. J. Exp. Med. 205, 2537-2550 (2008).

95. Edinger, A. L. et al. Differential utilization of CCR5 by macrophage and T cell tropic simian immunodeficiency virus strains. Proc. Natl Acad. Sci. USA 94, 4005-4010 (1997).

96. Kirchhoff, F. et al. Simian immunodeficiency virus variants with differential T-cell and macrophage tropism use CCR5 and an unidentified cofactor expressed in CEM 174 cells for efficient entry. J. Virol. 71, 6509-6516 (1997).
97. Weissman, D. et al. Macrophage-tropic HIV and SIV envelope proteins induce a signal through the CCR5 chemokine receptor. Nature 389, 981-985 (1997).

98. Keele, B. F. et al. Identification and characterization of transmitted and early founder virus envelopes in primary HIV-1 infection. Proc Natl Acad. Sci. USA 105, 7552-7557 (2008). This study used super genome alignment-based sequence analysis to identify and examine the evolution of HIV Env on founder viruses in acutely infected humans.

99. Keele, B. F. et al. Low-dose rectal inoculation of rhesus macaques by SIVsmE660 or SIVmac251 recapitulates human mucosal infection by HIV-1. J. Exp. Med. 206, 1117-1134 (2009).

100. McDermott, A. B. et al. Repeated low-dose mucosal simian immunodeficiency virus SIVmac239 challenge results in the same viral and immunological kinetics as high-dose challenge: a model for the evaluation of vaccine efficacy in nonhuman primates. J. Virol. 78 , 3140-3144 (2004)

This study examined a repeated low-dose SIV challenge strategy in rhesus macaques designed to more closely mimic mucosal infection with HIV than previous strategies.

101. Van Damme, N. et al. The interferon-induced protein BST-2 restricts HIV- 1 release and is downregulated from the cell surface by the viral Vpu protein. Cell Host Microbe 3, 245-252 (2008).

102. Van Damme, N. \& Guatelli, J. HIV-1 Vpu inhibits accumulation of the envelope glycoprotein within clathrin-coated, Gag-containing endosomes. Cell. Microbiol. 10, 1040-1057 (2008).

103. Neil, S. J., Zang, T. \& Bieniasz, P. D. Tetherin inhibits retrovirus release and is antagonized by HIV-1 Vpu. Nature 451, 425-430 (2008).

104. Cullen, B. R. HIV-1 auxiliary proteins: making connections in a dying cell. Cell 93, 685-692 (1998).

105. Bieniasz, P. D. Intrinsic immunity: a front-line defense against viral attack. Nature Immunol. 5, 1109-1115 (2004).

106. Sheehy, A. M., Gaddis, N. C., Choi, J. D. \& Malim, M. H Isolation of a human gene that inhibits HIV-1 infection and is suppressed by the viral Vif protein. Nature $\mathbf{4 1 8}$ 646-650 (2002).

107. Stremlau, M. et al. The cytoplasmic body component TRIM5 $\alpha$ restricts HIV- 1 infection in Old World monkeys. Nature 427, 848-853 (2004). This study identified rhesus macaque TRIM5 $\alpha$ as a species-specific restriction factor for blocking HIV-1 infection.

108. Hatziioannou, T. et al. A macaque model of HIV-1 infection. Proc. Natl Acad. Sci. USA 106, 4425-4429 (2009).

109. Hatziioannou, T. et al Generation of simian-tropic HIV-1 by restriction factor evasion. Science 314,95 (2006)

110. Kamada, K. et al. Generation of HIV-1 derivatives that productively infect macaque monkey lymphoid cells. Proc Natl Acad. Sci. USA 103, 16959-16964 (2006).

11. Dudley, D. M., Wentzel, J. L., Lalonde, M. S Veazey, R. S. \& Arts, E. J. Selection of a simian-human immunodeficiency virus strain resistant to a vaginal microbicide in macaques. J. Virol. 83, 5067-5076 (2009).

112. Pekrun, K. et al. Evolution of a human immunodeficiency virus type 1 variant with enhanced replication in pig-tailed macaque cells by DNA shuffling. J. Virol. 76, 2924-2935 (2002).

113. Shibata, R. \& Adachi, A. SIV/HIV recombinants and their use in studying biological properties. AIDS Res. Hum. Retroviruses 8, 403-409 (1992).

114. Box, G. E. P. \& Draper, N. R. Empirical Model-Building and Response Surfaces (Wiley, New York, 1987).

115. Xu, R. et al. Characterization of immune responses elicited in macaques immunized sequentially with chimeric VEE/SIN alphavirus replicon particles expressing SIVGag and/or HIVEnv and with recombinant HIVgp 140Env protein. AIDS Res. Hum Retroviruses 22, 1022-1030 (2006).

116. Gorse, G. J. et al. Safety and immunogenicity of cytotoxic T-lymphocyte poly-epitope, DNA plasmid (EP HIV-1090) vaccine in healthy, human immunodeficiency virus type 1 (HIV-1)-uninfected adults. Vaccine 26, 215-223 (2008).

117. Subbramanian, R. A. et al. Magnitude and diversity of cytotoxic-T-lymphocyte responses elicited by multiepitope DNA vaccination in rhesus monkeys. J. Virol. 77, 10113-10118 (2003).
118. Wilson, C. C. et al. Clinical phase 1 testing of the safety and immunogenicity of an epitope-based DNA vaccine in human immunodeficiency virus type 1 -infected subjects receiving highly active antiretroviral therapy. Clin. Vaccine Immunol. 15 986-994 (2008)

119. Nehete, P. N. et al. Selective induction of cellmediated immunity and protection of rhesus macaques from chronic $\mathrm{SHIV}_{\mathrm{KU} 2}$ infection by prophylactic vaccination with a conserved HIV-1 envelope peptide-cocktail. Virology 370, 130-141 (2008).

120. Spearman, P. et al. Safety and immunogenicity of a CTL multiepitope peptide vaccine for HIV with or without GM-CSF in a phase I trial. Vaccine 27 243-249 (2009)

121. Buchbinder, S. P. et al. Efficacy assessment of a cellmediated immunity HIV-1 vaccine (the Step Study): a double-blind, randomised, placebo-controlled, test-of-concept trial. Lancet 372, 1881-1893 (2008)

122. Casimiro, D. R. et al. Comparative immunogenicity in rhesus monkeys of DNA plasmid, recombinant vaccinia virus, and replication-defective adenovirus vectors expressing a human immunodeficiency virus type 1 gag gene. J. Virol. 77, 6305-6313 (2003).

123. Priddy, F. H. et al. Safety and immunogenicity of a replication-incompetent adenovirus type 5 HIV-1 clade B gag/pol/nef vaccine in healthy adults. Clin. Infect. Dis. 46, 1769-1781 (2008).

124. Pal, R. et al. ALVAC-SIV-gag-pol-env-based vaccination and macaque major histocompatibility complex class (A*01) delay simian immunodeficiency virus SIVmacinduced immunodeficiency. J. Virol. 76, 292-302 (2002).

125. Pal, R. et al. Systemic immunization with an ALVAC-HIV-1/protein boost vaccine strategy protects rhesus macaques from $\mathrm{CD} 4{ }^{+} \mathrm{T}$-cell loss and reduces both systemic and mucosal simian-human immunodeficiency virus SHIVKU2 RNA levels. J. Virol 80, 3732-3742 (2006).

126. Villefroy, P. et al. SIV escape mutants in rhesus macaques vaccinated with NEF-derived lipopeptides and challenged with pathogenic SIVmac251. Virol. J. 3, 65 (2006)

127. Letvin, N. L et al. Preserved CD4 ${ }^{+}$central memory $\mathrm{T}$ cells and survival in vaccinated SIV-challenged monkeys. Science 31 2, 1530-1533 (2006).

128. Robinson, H. L. et al. Immunogenicity in macaques of the clinical product for a clade B DNA/MVA HIV vaccine: elicitation of IFN- $\gamma$, IL-2, and TNF- $\alpha$ coproducing CD4 and CD8 T cells. AIDS Res. Hum. Retroviruses 23, 1555-1562 (2007)

129. Weber, J. et al. 'Chemical condoms' for the prevention of HIV infection: evaluation of novel agents against SHIV(89.6PD) in vitro and in vivo. AIDS 15 , 1563-1568 (2001).

130. Stephenson, J. HIV studies: progress in microbicides, dead end for an immune-boosting strategy. JAMA 301, 1421-1422 (2009).

131. Baden, L. R et al. Phase I trials of a prophylactic HIV-1 gag vaccine with IL-12 or IL-15 DNA molecular adjuvant (HVTN 060 and 063). Antiviral Ther. 12, (Suppl. 4) P06-11 (2007).

\section{Acknowledgements}

We acknowledge P. Offit, M. Connors, J. White and S. Plotkin for contributions and/or critical reading of this manuscript. Support from the US National Institutes of Health (NIH) AIDS Research and Reference Reagents Program (NIH-ARRR) and the University of Pennsylvania Centers for AIDS Research (CFAR) is also acknowledged. This work was supported in part by grants from the NIH to D.J.S. (T32 AI070099) and D.B.W.

\section{Competing financial interests}

The authors declare competing financial interests: see Web version for details.

DATABASES

UniProtKB: http://www.uniprot.org APOBEC 3G |CCR5 |CD4 | interferon- $\gamma$ | perforin | TRIM5a

FURTHER INFORMATION

David B. Weiner's homepage: http://www.med.upenn.edu/ camb/faculty/gt/weiner.html

UNAIDS homepage: http://www.unaids.org

ALL LINKS ARE ACTIVE IN THE ONLINE PDF 